\title{
Morphology, Thermal, and Mechanical Characterization of Bark Cloth from Ficus natalensis
}

\author{
Samson Rwawiire, ${ }^{1,2}$ George William Luggya, ${ }^{2}$ and Blanka Tomkova ${ }^{1}$ \\ ${ }^{1}$ Department of Material Engineering, Technical University of Liberec, Studentská 2, 46117 Liberec, Czech Republic \\ ${ }^{2}$ Department of Textile and Ginning Engineering, Busitema University, P.O. Box 236, Tororo, Uganda
}

Correspondence should be addressed to Samson Rwawiire; rsammy@eng.busitema.ac.ug

Received 4 July 2013; Accepted 31 July 2013

Academic Editors: M. Jaroszewski, A. A. Merati, G. Schoukens, and C. Wang

Copyright (C) 2013 Samson Rwawiire et al. This is an open access article distributed under the Creative Commons Attribution License, which permits unrestricted use, distribution, and reproduction in any medium, provided the original work is properly cited.

\begin{abstract}
The United Nations Educational, Scientific and Cultural Organization (UNESCO) proclaimed in 2005 that Ugandan bark cloth is largely produced from mutuba tree (Ficus natalensis) as a "Masterpiece of the Oral and Intangible Heritage of Humanity." An exploratory investigation of bark cloth a nonwoven material produced through a series of pummeling processes from mutuba tree in Uganda is fronted as a prospective engineering natural fabric. Bark cloth was obtained from Ficus natalensis trees in Nsangwa village, Buyijja parish in Mpigi district, Central Uganda. The morphology of the fabric was investigated using scanning electron microscope (SEM). thermal behavior of the fabric was studied using thermagravimetric analysis (TGA) and differential scanning calorimetry (DSC). Fourier transform infrared spectroscopy was used to evaluate the surface functional groups. The fabric was subjected to alkaline treatment for six hours at room temperature in order to study the change in fabric thermal properties so as to set a base for applications in biodegradable composites. Findings show that the natural nonwoven fleece is stable below $200^{\circ} \mathrm{C}$; alkaline treatment positively influences the thermal behavior by increasing the onset of cellulose degradation temperature. The fabric morphology showed that it is made up of fairly ordered microfibers which can be beneficial for nanocomposites.
\end{abstract}

\section{Introduction}

Worldwide, researchers are embroiled in a race for niche products whereby industries can boost production processes as well as putting into consideration the laws of sustainability. The quest for structural materials, which are environmentally friendly, to mitigate global warming effects is on the agenda of industrialized nations and recommendations are put forward for production of recyclable, biodegradable products or materials with zero emissions.

Transition to a more sustainable biobased economy, as a political consequence of the Kyoto protocol on global climate change, includes a shift from petrochemical to renewable sources.

The ecological "green" image of cellulosic fibers is the leading argument for innovation and development of products which are biodegradable and can be applied to automotive industries [1-3], building and construction [4], geotextiles, and agricultural products $[5,6]$.
Plant-based fibers like flax, hemp, nettle, and kenaf which have been used to provide fiber in the Western world have attracted renewed interest in textile and industrial composite applications [6-9].

The need for lightness of materials with superb performance characteristics has sparked interest in lightweight composite materials. The front seat drivers of low density coupled with excellent mechanical properties of natural fibrous composites have a double impact in this respect. Carbon, glass, and Kevlar are the leading providers of fiber for composite reinforcement. The bottleneck is that their feedstock is from petroleum sources and has disposal concerns. With the dwindling petroleum resources coupled with high prices $[10$, 11], fiber from lignocellulosic materials will play a major role in the transition from synthetic to environmentally friendly biodegradable green composites whose feedstock is from wood and plants.

Numerous researches are flowing in on use of novel plants for production of fiber such as Sansevieria $[12,13]$, 


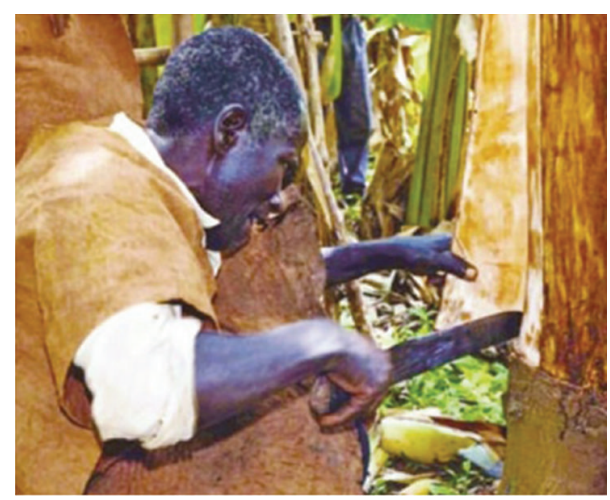

(a)

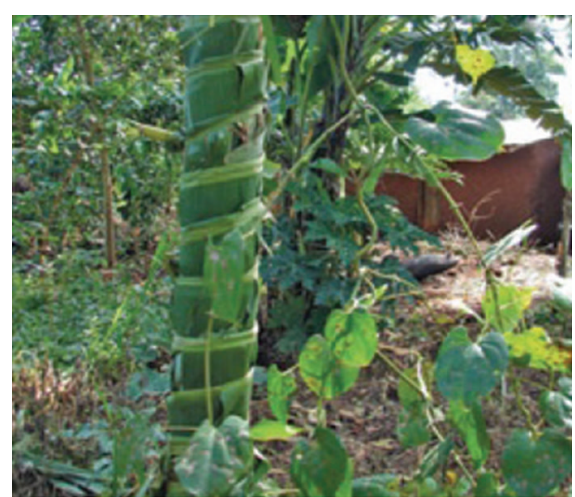

(b)

Figure 1: (a) A man dressed in bark cloth harvesting bark from mutuba tree. (b) Protecting the tree. Image courtesy "Fumiko Ohinata/ UNESCO".

piassava [14], okra [15, 16], palm oil [17], and carnauba [18]. Uganda like many tropical countries has a variety of plants with potential of fiber production. Some are domestically cultivated such as pineapples, bananas, okra, sisal, and oil palm, others grow in the wild and for example, sansevieria, nettle, ramie, and so forth.

According to the United Nations Educational, Scientific and Cultural Organization (UNESCO), bark cloth has been in production in Uganda for over six centuries; however, the nonwoven fleece which is produced through a series of pummeling processes has been confined to cultural regalia won at coronation of kings by Baganda a tribe in central Uganda and was also utilized during funerals and other witchcraft-related ceremonies. The technology transfer of bark cloth production from the elderly to the youth has been impeded by rural to urban migration of the youth and influence to modernization. That notwithstanding, in 2005, UNESCO proclaimed it as a "Masterpiece of the Oral and Intangible Heritage of Humanity" [19]. In the $70 \mathrm{~s}$ and $80 \mathrm{~s}$, production of bark cloth was banned in Uganda and was revived in the $90 \mathrm{~s}$. Due to the ban, the number of bark cloth crafts men was reduced and they were marginalized in society; however, due to increased imports of textiles from Asia especially China, bark cloth production is rendered unprofitable with few buyers. Value addition of bark cloth through engineering the fabric for probably composite reinforcement will create sustainable development of the rural communities and will once again lead to vibrant communities and increased bark cloth production. Bark cloth terracotta in color from Ficus natalensis and Antiaris toxicaria is largely produced in Uganda and it is possible to be applied in composite reinforcement [1].

The front seat drivers and prospects of bark cloth are because it is a naturally occurring fabric meaning that it is biodegradable, cheap, low-specific weight, and so forth. The fact that it is a natural nonwoven material is advantageous whereby it can be applied as a starting material for heat insulation and composite products. The drawbacks are that it is hydrophilic in nature, tedious, and has lengthy extraction processes coupled with lack of mechanized equipment for extraction.
In this study, an exploratory investigation of nonwoven fabric from the inner bark of mutuba tree (Ficus natalensis) is characterized. The trees grow naturally in Central Uganda and do not need fertilizers. Trees preserved for the purpose of bark cloth production are well tendered such that the stem has no roots to propagate on it.

Despite the fact that bark cloth has been around dating back as far as 13th century, there has been limited data or scientific study on bark cloth. Therefore, in this study, for the first time we present the microstructure, static, thermal, and mechanical properties of bark cloth.

\section{Materials and Methods}

2.1. Extraction. The extraction of the naturally occurring nonwoven as described by Rwawiire et al. (2011) [20] starts with scrapping off the surface layer of the trunk to expose the fresh raw bark using a sharp blade. The blade is held at an angle such that only the surface layer is removed and also avoids damaging the tree and fresh bark (Figure 1(a)). A ring is then cut with a knife on both ends of the scrapped stem that reflected the length of the bark cloth that was to be produced. At the same time, a vertical slit is made from the top of the stem to bottom. With the help of a wedged tool locally known as ekiteteme, carved out of the innermost part of a banana stem, the bark is easily peeled off starting from the base slowly moving upwards.

For environmental sustainability, the debarked stem is wrapped with banana leaves, (Figure 1(b)) which acts as bandages to prevent dehydration. These are usually removed after a week giving way for growth of fresh bark. (Figure 2) is the detailed process of production of bark cloth. The extracted bark is then burnt using dried banana leaves to soften it prior to pummeling process which includes different welldesigned wooden grooved hammers. Pummeling is usually done under a shade to prevent direct sunrays from creating creases in the bark cloth. After pummeling, the bark cloth is sundried for 3 hours every day for 6 days giving it a rich deep red-brown color and then repounded to smoothen the cloth surfaces. Drying involves stretching the wet fresh bark cloth 


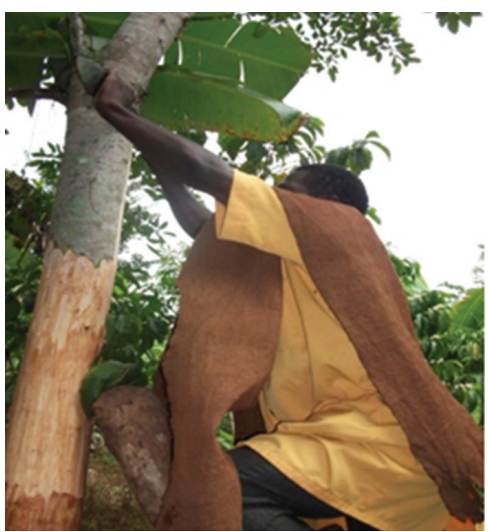

(a)

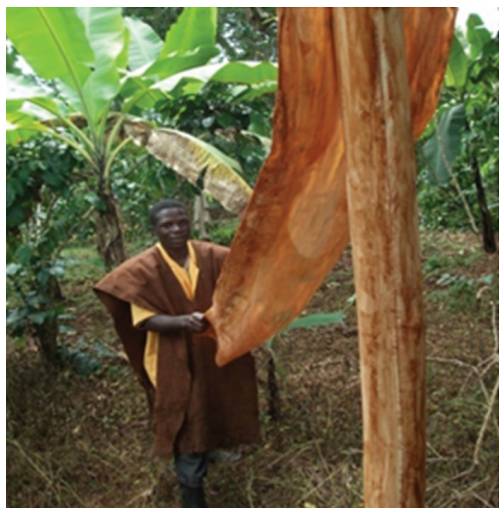

(d)

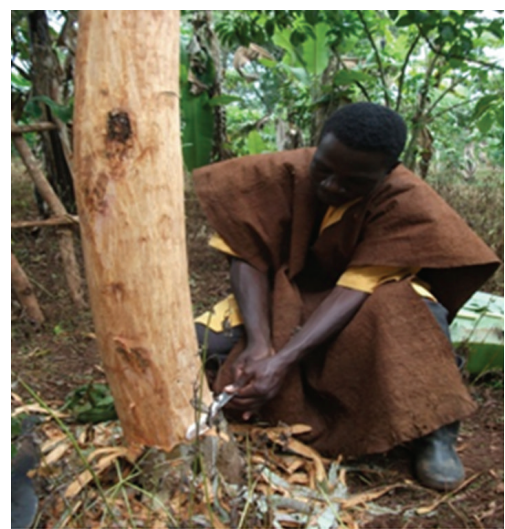

(b)

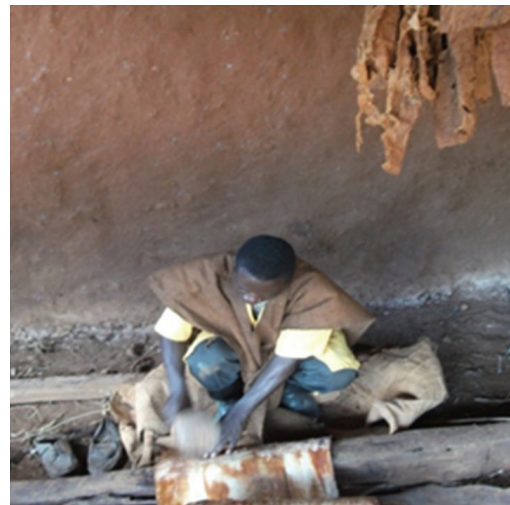

(e)

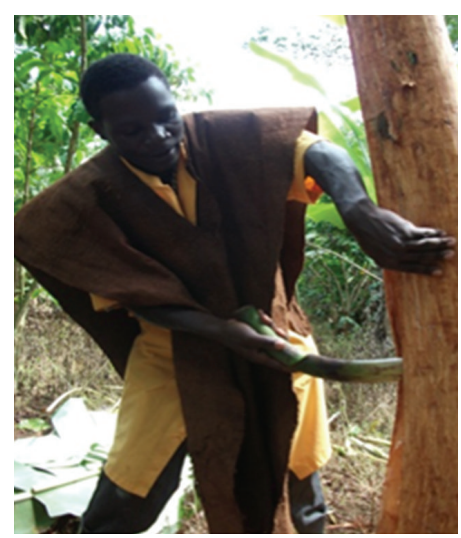

(c)

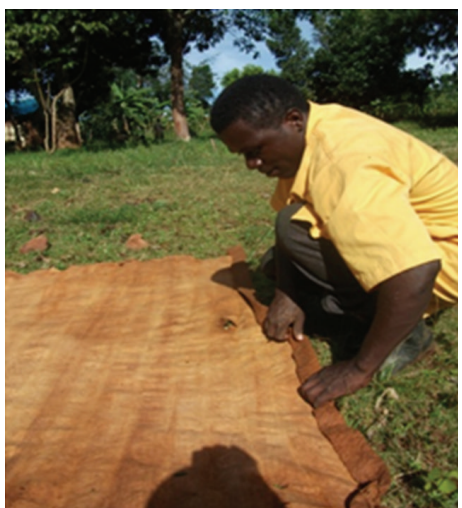

(f)

FIGURE 2: Extraction of bark cloth from mutuba tree (a) and (b) scrapping of surface layer. (c) Debarking the tree using a banana stalk. (d) Peeling off the bark. (e) Pummeling process using grooved wooden hammers. (f) Dried and finished bark cloth.

using heavy loads at its perimeter to retain its dimensions on drying.

2.2. Fabric Thickness. The fabric thickness was obtained using UNI Thickness Meter. Measurement is done at different positions; the probe with a disc delivers a pressure of $1 \mathrm{kPa}$ over an area of $25 \mathrm{~cm}^{2}$ for $30 \mathrm{~s}$; then the thickness is obtained in $\mathrm{mm}$. Ten readings were obtained and an average was statistically computed.

2.3. Chemical Treatment. The bark cloth was subjected to alkali treatment of $5 \% \mathrm{NaOH}$ solution. The bark cloth weighing $200.37 \mathrm{~g}$ was soaked in it for $6 \mathrm{hrs}$ at room temperature thereafter thoroughly cleaned using distilled water to remove the alkali together with other impurities and then dried at room temperature.

\subsection{Characterization Methods}

2.4.1. Fabric Morphology. The surface morphologies were investigated using a Vegas-Tescan scanning electron microscope with accelerating voltage of $20 \mathrm{KV}$.

2.4.2. Fourier Transform Infrared Spectroscopy (FTIR). Nicolet iN10 MX Scanning FTIR Microscope was used to provide the spectrum of the sample. The infrared absorbance spectrum of each sample was obtained in the range of 4000 $700 \mathrm{~cm}^{-1}$.

2.4.3. Thermogravimetric Analysis (TGA). Thermogravimetric analysis was carried out using a Mettler Toledo TGA/ SDTA $851^{\mathrm{e}}$ under a dynamic nitrogen atmosphere heating from room temperature $\left(25^{\circ} \mathrm{C}\right)$ to $500^{\circ} \mathrm{C}$ at a heating rate of $10^{\circ} \mathrm{C} / \mathrm{min}$. Weight changes of the fiber samples weighing approximately 7-8 $\mathrm{mg}$ were measured.

2.4.4. Differential Scanning Calorimeter Analysis (DSC). The Perkin Elmer Differential Scanning Calorimeter DSC6 was used. Samples weighing approximately $10 \mathrm{mg}$ using Waga Torsyjna-WT scale were placed in aluminum pans and sealed. The specimens were heated in an inert nitrogen atmosphere from room temperature $\left(25^{\circ} \mathrm{C}\right)$ to $450^{\circ} \mathrm{C}$ at a heating rate of $10^{\circ} \mathrm{C} / \mathrm{min}$.

2.4.5. Fourier Transform Infrared Spectroscopy. Nicolet iN10 MX Scanning FTIR Microscope was used to provide the spectrum of the sample. The FT-IR spectrum of each sample was obtained in the range of $4000-700 \mathrm{~cm}^{-1}$ in the transmission mode.

2.4.6. Mechanical Properties. The fabric strength was quantified through measurements of samples for the bursting 

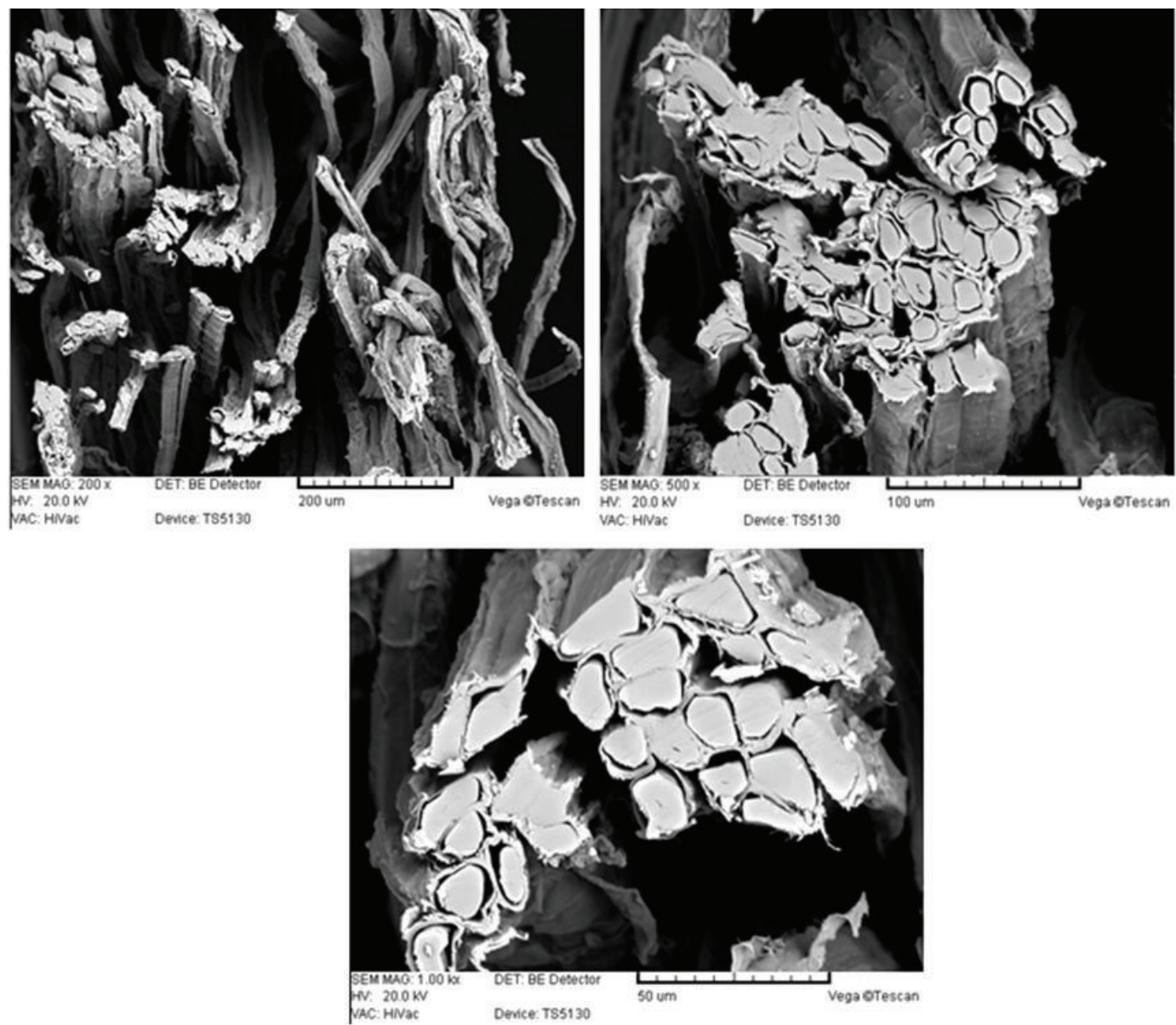

FIGURE 3: SEM morphology of transverse sections of bark cloth at magnifications 200x, 500x, and 1000x.

strength of the nonwoven fleece. Samples measuring $5 \mathrm{~cm}$ by $15 \mathrm{~cm}$ were tested using a Labotech fabric tensile testing machine at room temperature.

\section{Results and Discussion}

3.1. Fabric Morphology. SEM was used to study the fabric morphology and images of the microstructure of the fabrics were obtained. The front seat drivers of SEM against optical microscope are that SEM has a high depth of field even at high magnifications. Ghassemieh et al. (2002) [21] showed that by using SEM for fabric morphology, more fibers in the fabric are in focus and are included in the image compared with other methods. In order to show a representative image of the fabric, magnification was optimized by using magnifications of 100,500 , and 1000. Several images were taken in order to show the microstructure of the fabric and to pinpoint the fiber orientations in bark cloth.

Figure 3 shows the SEM images at different magnifications. The transverse sections of the fabric show that the structure is entirely made up of solid cellulosic fibers without lumens. The microfibers are oval in shape bonded by lignin and hemicelluloses with diameters between 10 and $20 \mu \mathrm{m}$. The images also show that bark cloth can be a rich source for cellulose microfibrils for nanocomposites.
The top surface of bark cloth (Figure 4) shows the crosslinking of naturally bonded fibers with oval-shaped pores in the fabric created by voids arising from the fiber crosslinkages. Just like the top surface, the bottom surface of the fabric shows a dense packing of the fibers as seen in (Figure 4). The lignin and hemicelluloses which bind the microfibers together are responsible for the fabric's thermal comfort properties. The microfibers are aligned in a fairly orderly manner forming cross-linkages.

There is slight change in the color appearance of the fabric after alkaline treatment (Figure 5); however, after drying, the fabric tender soft touch was lost and it adopted a rigid feeling. The slightly rigid feeling after alkaline treatment is attributed to a decrease in the moisture content, thus leaving hard rigid fibers compared to the untreated fabric.

3.2. Fabric Thickness. The mean fabric thickness was computed as $1.084 \mathrm{~mm}$ from five samples of readings at different positions of the fabric.

3.3. Fabric Strength. The mean strength of the fabric in the fiber direction was $101.7 \mathrm{~N}$ and $23.5 \mathrm{~N}$ transverse. Since bark cloth fibers are aligned at angles (Figure 6), the fabric samples were cut such that the tests are applied in longitudinal (fiber direction) and transverse directions (perpendicular). 


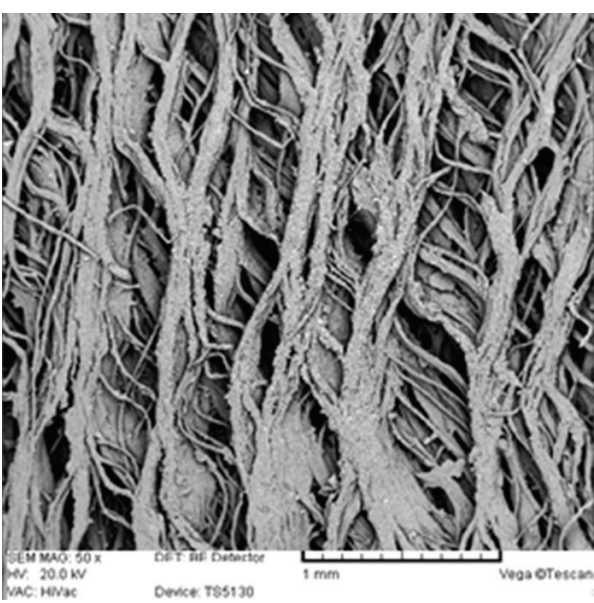

(a)

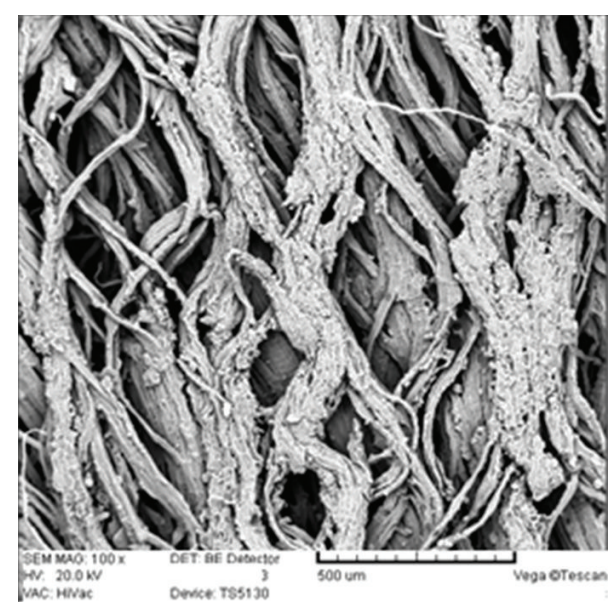

(b)

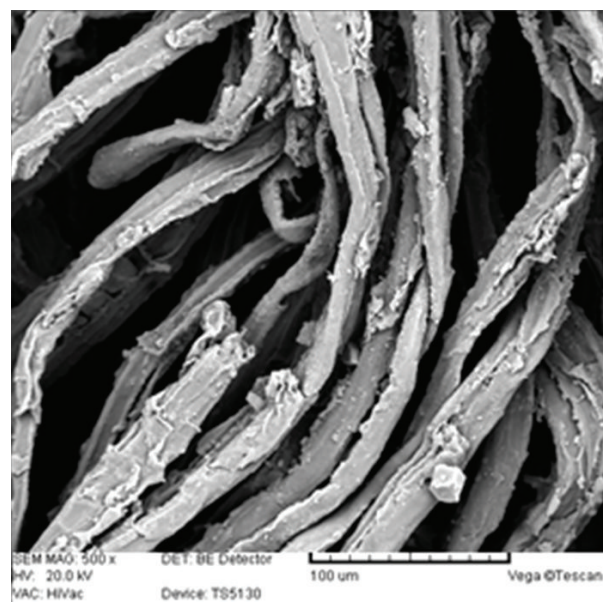

(c)

FIGURE 4: SEM morphology of top surface of untreated bark cloth at magnifications (a) 50x, (b) 100x, and (c) 500x.

3.4. Surface Functional Groups. Functional groups assignments and their respective bonding interactions of bark cloth can be deduced using Fourier transform infrared $s$ pectroscopy (Figure 7). Natural fibrous-specific bands and their corresponding bonding interactions have been studied by numerous researchers [22-38]. There is a variation in the reported bands from one researcher to another; however, the difference is not too significant because most natural fibrous materials are made up of celluloses, hemicelluloses, and lignin.

A broad absorption band at $3363 \mathrm{~cm}^{-1}$ is due to $\mathrm{O}-\mathrm{H}$ stretching vibrations of cellulose and hemicelluloses. The band at $2929 \mathrm{~cm}^{-1}$ corresponds to $\mathrm{CH}_{2}$ and $\mathrm{CH}_{3}$ stretching vibrations [35]. The band at $1740 \mathrm{~cm}^{-1}$ is due to carbonyl groups $(\mathrm{C}=\mathrm{O})$ stretching and vibration of acetyl groups of hemicelluloses $[15,32,35]$.

After this peak, the sudden leveling off shows that the hemicelluloses are removed from the fiber. Aromatic vibration of benzene ring in lignin may be at $1615 \mathrm{~cm}^{-1}$. The absorption band at $1529 \mathrm{~cm}^{-1}$ was owing to $\mathrm{CH}_{2}$ bending in lignin, whereas the peak at $1445 \mathrm{~cm}^{-1}$ was due to $\mathrm{O}-\mathrm{H}$ inplane bending [35]. The peak at $1380 \mathrm{~cm}^{-1}$ was assigned to $\mathrm{CH}$ symmetric bending. The band at $1274 \mathrm{~cm}^{-1}$ may correspond to $\mathrm{C}-\mathrm{O}$ stretching of acetyl group of lignin [26, 35, 37]. The band at $1157 \mathrm{~cm}^{-1}$ may be due to $\mathrm{C}-\mathrm{O}-\mathrm{C}$ asymmetrical stretching in cellulose. The broad peak at $1056 \mathrm{~cm}^{-1}$ is due to $-\mathrm{C}-\mathrm{O}-\mathrm{C}-$ pyranose ring skeletal vibration [35]. The band at $779 \mathrm{~cm}^{-1}$ represents glycosidic $-\mathrm{C}-\mathrm{H}$ deformation, with a ring vibration contribution and $-\mathrm{O}-\mathrm{H}$ bending which are the characteristics of $\beta$-glycosidic linkages between the anhydroglucose units in cellulose $[27,30,35]$.

3.5. Thermal Properties. Nascimento et al. (2012) [14] showed that for natural fibers the thermogravimetric behavior is directly proportional to the chemical constituents of the fibers. Figure 8 shows the thermogram of bark cloth. The first stage from $25^{\circ} \mathrm{C}$ to $100^{\circ} \mathrm{C}$ is attributed to evaporation of water accounting for about $10 \%$ loss in weight.

The second stage accounting to about $70 \%$ weight loss starts from about $220^{\circ} \mathrm{C}$ to $370^{\circ} \mathrm{C}$ with a maximum decomposition temperature corresponding to around $325^{\circ} \mathrm{C}$. The temperature range $200^{\circ} \mathrm{C}-315^{\circ} \mathrm{C}$ corresponds to the cleavage of glycosidic linkages of cellulose which leads to formation of $\mathrm{H}_{2} \mathrm{O}, \mathrm{CO}_{2}$, alkanes, and other hydrocarbon derivatives [35]. 


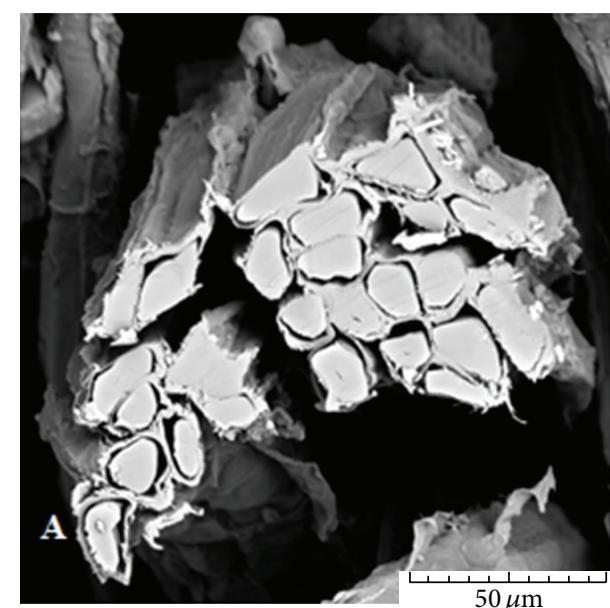

(a)

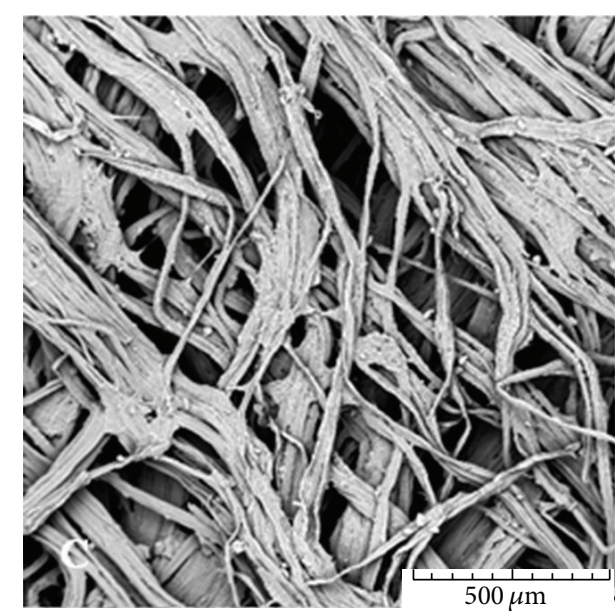

(c)

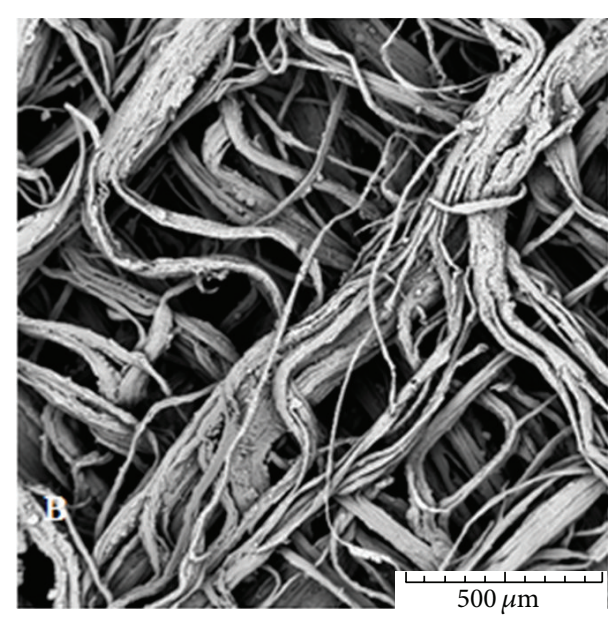

(b)

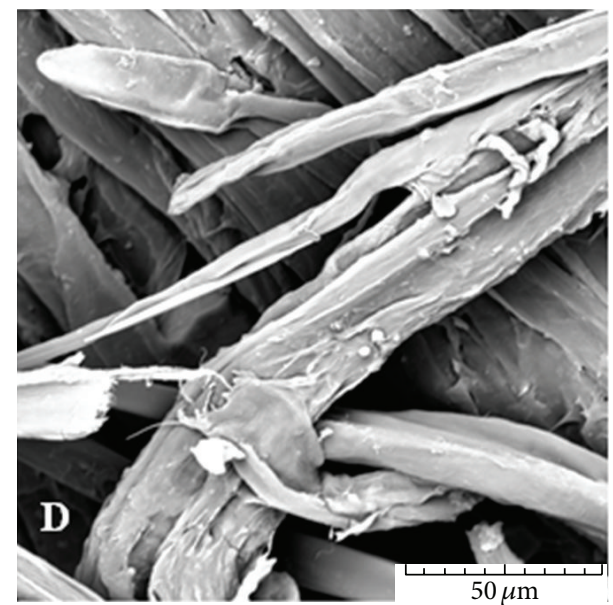

(d)

FIGURE 5: SEM morphology of treated bark cloth at magnifications (a) 50x, (b) and (c) 100x, and (d) 500x.

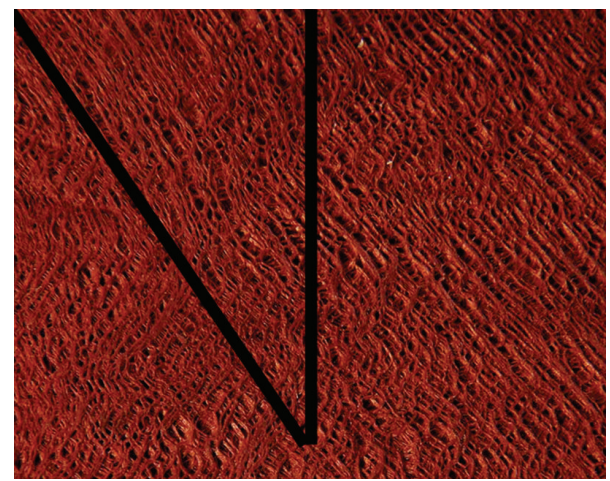

FIgURE 6: Approximate fiber arrangement of bark cloth.

The last stage of decomposition starting from around $370^{\circ} \mathrm{C}$ corresponds to $20 \%$ loss in weight is due to char or other decomposition reactions [14].

Bark cloth thermograms have showed that the fabric is stable below $200^{\circ} \mathrm{C}$; therefore, alternatives of composite fiber reinforcement can be explored provided that the working

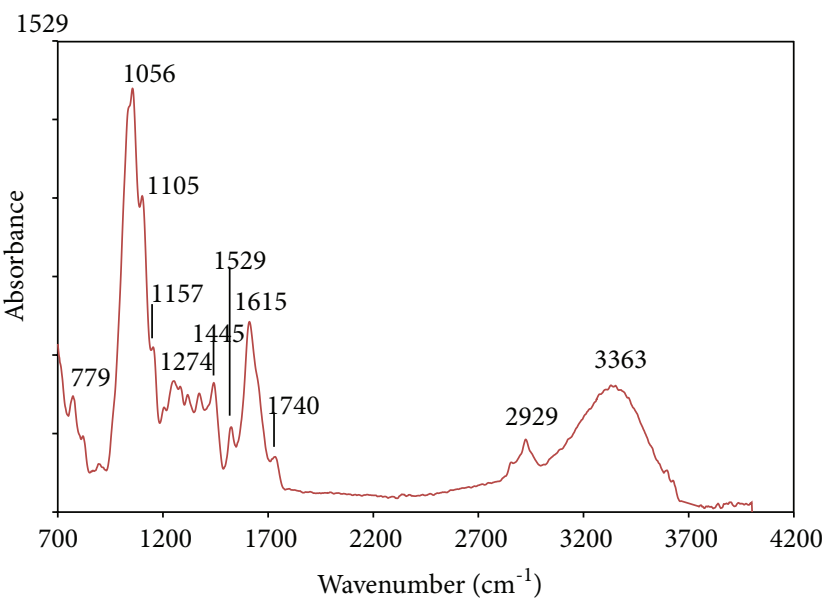

FIGURE 7: Fourier transform infrared spectra of bark cloth.

and production temperature of composites is kept under this temperature. 


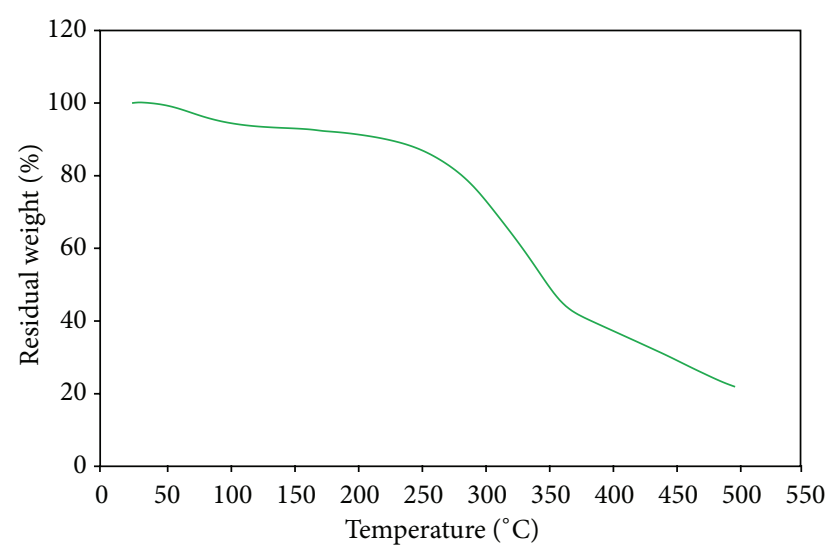

Figure 8: Thermogram of bark cloth.

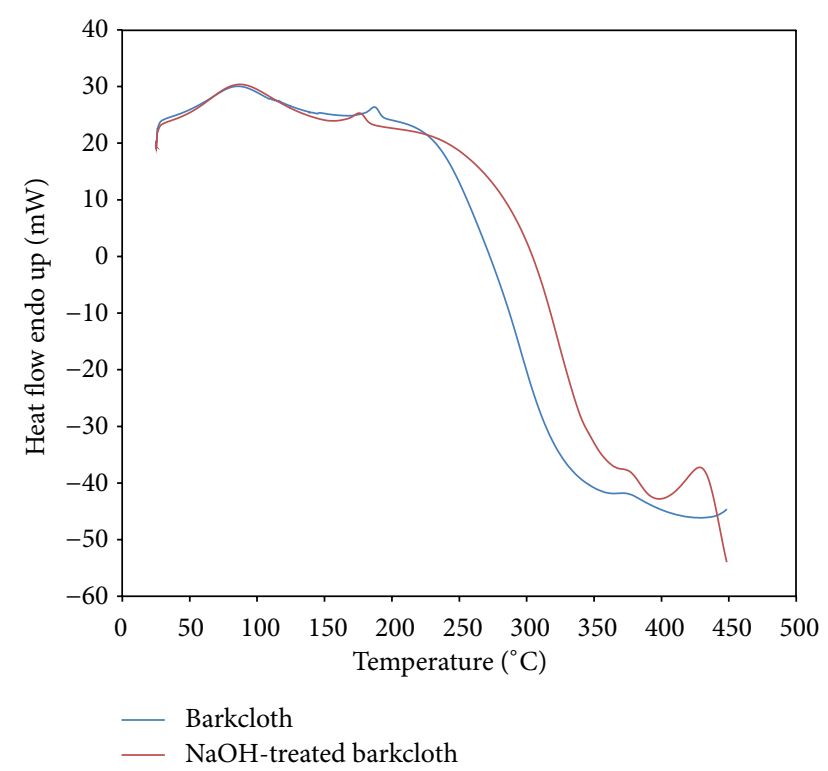

FIGURE 9: Differential scanning calorimetry of untreated and alkaline-treated bark cloth.

The first peak at $85.35^{\circ} \mathrm{C}$ (Figure 9) corresponds to water loss, whereas a small peak at $187^{\circ} \mathrm{C}$ with heat $13.76 \mathrm{~J} / \mathrm{g}$ may be due to decomposition of hemicelluloses. Onset at $228.87^{\circ} \mathrm{C}$ is due to decomposition of cellulose which is in agreement with the weight loss as can be observed from the TGA thermogram in Figure 8. There was no crystallization observed due to the fact the source is wood fiber from the bark of Ficus $n$. trees. The last peak at temperature $375.42^{\circ} \mathrm{C}$ is attributed to decomposition of lignin.

\section{Conclusion}

Bark cloth extracted from Ficus natalensis trees was characterized using fourier transform infrared spectroscopy, differential scanning calorimetry, thermogravimetric analysis, and scanning electron microscopy.

Bark cloth is a porous fabric made of cellulosic material; the microfibers were found to be aligned in a fairly orderly manner at angles close to $45^{\circ}$. Thermal properties of the fabric show that it is stable below temperatures of $200^{\circ} \mathrm{C}$; therefore, the fabric can be explored for composite reinforcement. It was observed that alkaline treatments positively influence the thermal properties of the fabric, raising the onset temperature of cellulose decomposition, meaning that if used for composite reinforcement, chemical surface treatments will improve the performance properties of bark cloth as reinforcement for composites.

\section{Acknowledgments}

The first author is grateful to God for life Busitema University for granting a study leave, and also to the Technical University of Liberec for funding the research.

\section{References}

[1] S. Rwawiire and W. Johnnie, "Natural fibers: a blue print for ecofriendly textiles and biocomposites," in Proceedings of 15th International Scientific and Practical Workshop: Physics of Fibrous Materials, pp. 67-73.

[2] United Nations Framework Convention on Climate Change, 1992.

[3] G. Koronis, A. Silva, and M. Fontul, "Green composites: a review of adequate materials for automotive applications," Composites $B$, vol. 44, no. 1, pp. 120-127, 2013.

[4] D. B. Dittenber and H. V. S. GangaRao, "Critical review of recent publications on use of natural composites in infrastructure," Composites A, vol. 43, no. 8, pp. 1419-1429, 2012.

[5] P. Methacanon, U. Weerawatsophon, N. Sumransin, C. Prahsarn, and D. T. Bergado, "Properties and potential application of the selected natural fibers as limited life geotextiles," Carbohydrate Polymers, vol. 82, no. 4, pp. 1090-1096, 2010.

[6] A. Mwasha, "Designing bio-based geotextiles for reinforcing an embankment erected on the soft soil," Materials and Design, vol. 30, no. 7, pp. 2657-2664, 2009.

[7] J. Summerscales, N. P. J. Dissanayake, A. S. Virk, and W. Hall, "A review of bast fibres and their composites-part 1: fibres as reinforcements," Composites A, vol. 41, no. 10, pp. 1329-1335, 2010.

[8] S. M. Sapuan and M. A. Maleque, "Design and fabrication of natural woven fabric reinforced epoxy composite for household telephone stand," Materials and Design, vol. 26, no. 1, pp. 65-71, 2005.

[9] F. P. La Mantia and M. Morreale, "Green composites: a brief review," Composites A, vol. 42, no. 6, pp. 579-588, 2011.

[10] A. K. Mohanty, M. Misra, and L. T. Drzal, Natural Fibers, Biopolymers, and Biocomposites, CRC Press, New York, NY, USA, 2005.

[11] T. D. Hapuarachchi, Development and characterisation of flame retardant nanoparticulate biobased polymer composites [Ph.D. thesis], 2010.

[12] V. S. Sreenivasan, S. Somasundaram, D. Ravindran, V. Manikandan, and R. Narayanasamy, "Microstructural, physico-chemical and mechanical characterisation of Sansevieria cylindrica fibres-an exploratory investigation," Materials and Design, vol. 32, no. 1, pp. 453-461, 2011. 
[13] K. Ramanaiah, A. V. R. Prasad, and K. H. C. Reddy, "Mechanical, thermophysical and fire properties of sansevieria fiberreinforced polyester composites," Materials and Design, vol. 49, pp. 986-991, 2013.

[14] D. C. O. Nascimento, A. S. Ferreira, S. N. Monteiro, R. C. M. P. Aquino, and S. G. Kestur, "Studies on the characterization of piassava fibers and their epoxy composites," Composites A, vol. 43, no. 3, pp. 353-362, 2012.

[15] I. M. de Rosa, J. M. Kenny, M. Maniruzzaman et al., "Effect of chemical treatments on the mechanical and thermal behaviour of okra (Abelmoschus esculentus) fibres," Composites Science and Technology, vol. 71, no. 2, pp. 246-254, 2011.

[16] E. Fortunati, D. Puglia, M. Monti, C. Santulli, M. Maniruzzaman, and J. M. Kenny, "Cellulose nanocrystals extracted from okra fibers in PVA nanocomposites," Journal of Applied Polymer Science, vol. 128, no. 5, pp. 3220-3230, 2013.

[17] M. A. N. Izani, M. T. Paridah, U. M. K. Anwar, M. Y. M. Nor, and P. S. H'ng, "Effects of fiber treatment on morphology, tensile and thermogravimetric analysis of oil palm empty fruit bunches fibers," Composites B, vol. 45, no. 1, pp. 1251-1257, 2013.

[18] J. D. D. Melo, L. F. M. Carvalho, A. M. Medeiros, C. R. O. Souto, and C. A. Paskocimas, "A biodegradable composite material based on polyhydroxybutyrate (PHB) and carnauba fibers," Composites B, vol. 43, no. 7, pp. 2827-2835, 2012.

[19] A report on Revitalisation of bark cloth making in UgandaUNESCO/Japanese Funds-in-Trust Project.

[20] S. Rwawiire, N. Catherine, K. S. Baker, and G. Davis, "Processing of natural fiber textile from Ficus natalensis and Antiaris toxicaria," in Proceedings of the 2nd International Symposium on Sustainable Development through Research in Natural Textile Fibers, Textile Products, Trade and Marketing, Kisumu, Kenya, March 2012.

[21] E. Ghassemieh, M. Acar, and H. Versteeg, "Microstructural analysis of non-woven fabrics using scanning electron microscopy and image processing-part 1: development and verification of the methods," Proceedings of the Institution of Mechanical Engineers L, vol. 216, no. 3, pp. 199-207, 2002.

[22] M. Åkerholm, B. Hinterstoisser, and L. Salmén, "Characterization of the crystalline structure of cellulose using static and dynamic FT-IR spectroscopy," Carbohydrate Research, vol. 339, no. 3, pp. 569-578, 2004.

[23] J. Biagiotti, D. Puglia, L. Torre et al., "A systematic investigation on the influence of the chemical treatment of natural fibers on the properties of their polymer matrix composites," Polymer Composites, vol. 25, no. 5, pp. 470-479, 2004.

[24] W. Liu, A. K. Mohanty, L. T. Drzal, P. Askel, and M. Misra, "Effects of alkali treatment on the structure, morphology and thermal properties of native grass fibers as reinforcements for polymer matrix composites," Journal of Materials Science, vol. 39, no. 3, pp. 1051-1054, 2004.

[25] L. Y. Mwaikambo and M. P. Ansell, "Chemical modification of hemp, sisal, jute, and kapok fibers by alkalization," Journal of Applied Polymer Science, vol. 84, no. 12, pp. 2222-2234, 2002.

[26] W. Liu, A. K. Mohanty, L. T. Drzal, P. Askel, and M. Misra, "Effects of alkali treatment on the structure, morphology and thermal properties of native grass fibers as reinforcements for polymer matrix composites," Journal of Materials Science, vol. 39, no. 3, pp. 1051-1054, 2004, Erratum in Journal of Materials Science, vol. 39, no. 6, p. 2271, 2004.

[27] A. Alemdar and M. Sain, "Biocomposites from wheat straw nanofibers: morphology, thermal and mechanical properties,"
Composites Science and Technology, vol. 68, no. 2, pp. 557-565, 2008.

[28] A. Alhuthali, I. M. Low, and C. Dong, "Characterisation of the water absorption, mechanical and thermal properties of recycled cellulose fiber reinforced vinyl-ester eco-nanocomposites," Composites B, vol. 43, no. 7, pp. 2772-2781, 2012.

[29] A. R. S. Neto, M. A. M. Araujo, F. V. D. Souza, L. H. C. Mattoso, and J. M. Marconcini, "Characterization and comparative evaluation of thermal, structural, chemical, mechanical and morphological properties of six pineapple leaf fiber varieties for use in composites," Industrial Crops and Products, vol. 43, pp. 529-537, 2013.

[30] S. Elanthikkal, U. Gopalakrishnapanicker, S. Varghese, and J. T. Guthrie, "Cellulose microfibres produced from banana plant wastes: isolation and characterization," Carbohydrate Polymers, vol. 80, no. 3, pp. 852-859, 2010.

[31] M. A. Al Maadeed, R. Kahraman, P. N. Khanam, and S. AlMaadeed, "Characterization of untreated and treated male and female date palm leaves," Materials and Design, vol. 43, pp. 526531, 2013.

[32] V. S. Sreenivasan, S. Somasundaram, D. Ravindran, V. Manikandan, and R. Narayanasamy, "Microstructural, physico-chemical and mechanical characterisation of Sansevieria cylindrica fibres-an exploratory investigation," Materials and Design, vol. 32, no. 1, pp. 453-461, 2011.

[33] V. S. Sreenivasan, S. Somasundaram, D. Ravindran, V. Manikandan, and R. Narayanasamy, "Microstructural, physico-chemical and mechanical characterisation of Sansevieria cylindrica fibres-an exploratory investigation," Materials and Design, vol. 32, no. 1, pp. 453-461, 2011.

[34] H. Deka, M. Misra, and A. Mohanty, "Renewable resource based "all green composites" from kenaf biofiber and poly(furfuryl alcohol) bioresin," Industrial Crops and Products, vol. 41, pp. 94101, 2012.

[35] Y. Seki, M. Sarikanat, K. Sever, and C. Durmuşkahya, "Extraction and properties of Ferula communis (chakshir) fibers as novel reinforcement for composites materials," Composites B, vol. 44, no. 1, pp. 517-523, 2013.

[36] J. Biagiotti, D. Puglia, L. Torre et al., "A systematic investigation on the influence of the chemical treatment of natural fibers on the properties of their polymer matrix composites," Polymer Composites, vol. 25, no. 5, pp. 470-479, 2004.

[37] W. Liu, A. K. Mohanty, L. T. Drzal, P. Askel, and M. Misra, "Effects of alkali treatment on the structure, morphology and thermal properties of native grass fibers as reinforcements for polymer matrix composites," Journal of Materials Science, vol. 39, no. 3, pp. 1051-1054, 2004.

[38] L. Y. Mwaikambo and M. P. Ansell, "Chemical modification of hemp, sisal, jute, and kapok fibers by alkalization," Journal of Applied Polymer Science, vol. 84, no. 12, pp. 2222-2234, 2002. 

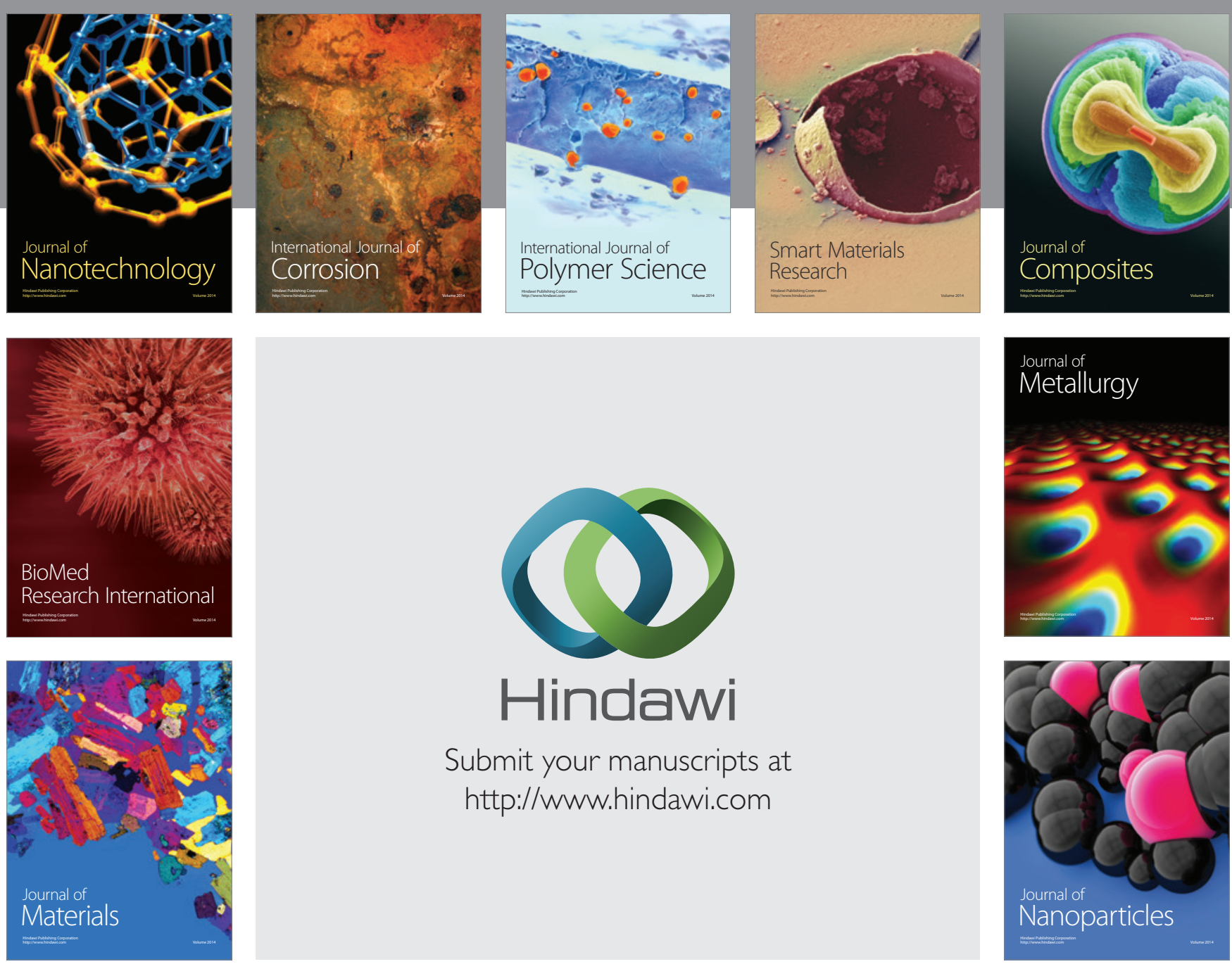

Submit your manuscripts at http://www.hindawi.com
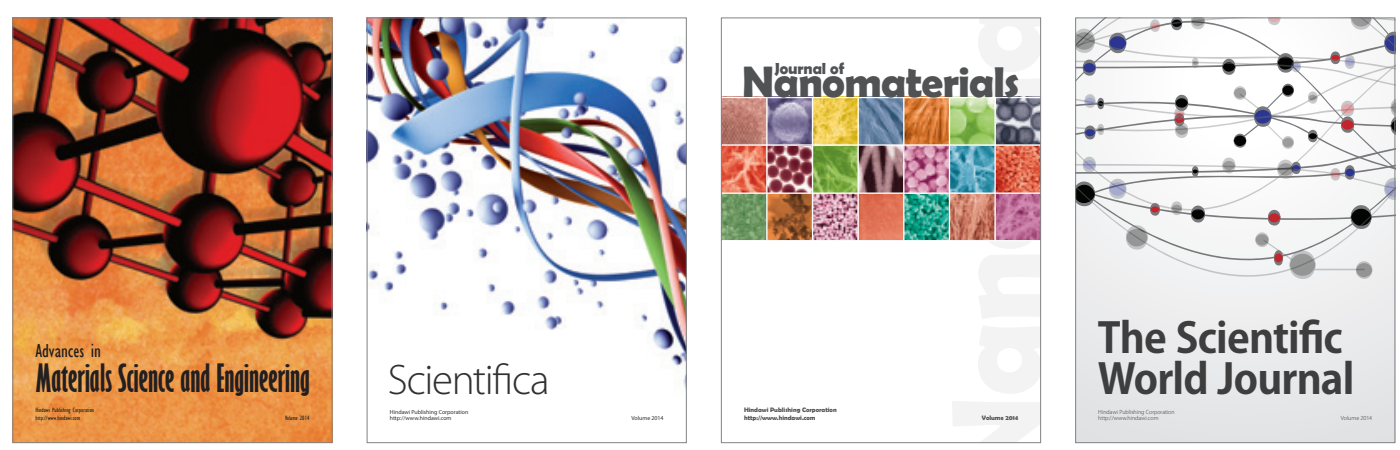

\section{The Scientific World Journal}
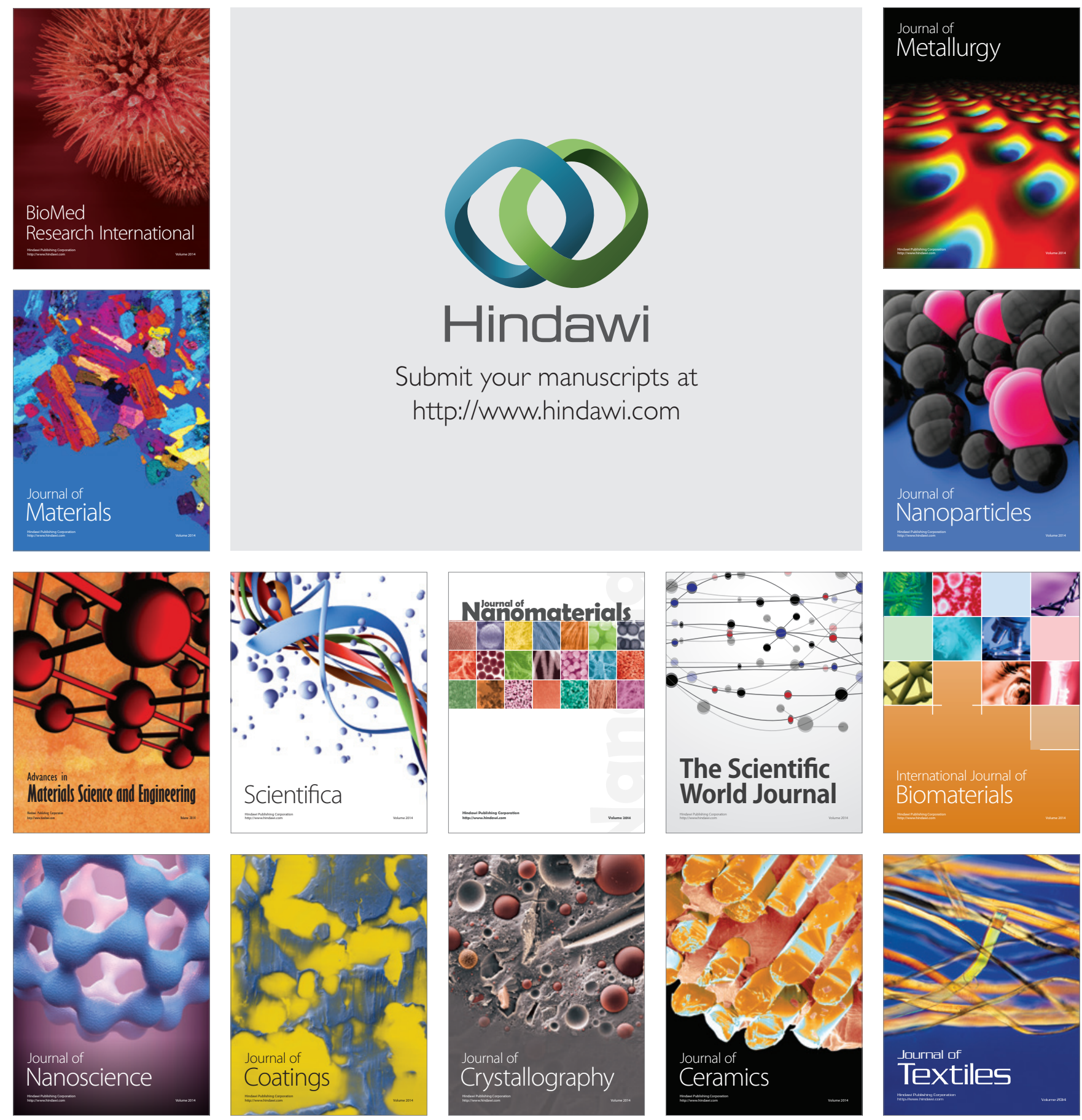